\title{
Dust impacts on radiative effects of black carbon aerosol in Central Asia
}

\author{
Ina Tegen ${ }^{1, *}$ and Bernd Heinold ${ }^{1}$ \\ ${ }^{1}$ Leibniz Institute for Tropospheric Research, Department Modelling of Atmospheric Processes, 04318 Leipzig, Germany
}

\begin{abstract}
The radiative effect of mineral dust and black carbon aerosol are investigated with aerosolclimate model simulations with fixed sea surface temperatures as boundary condition. The semi-direct effects of the absorbing aerosol are assessed as the residual between the total direct radiative effect and the instantaneous direct radiative effect of the aerosol species. For Central Asia the presence of mineral dust aerosol below a black carbon aerosol layer enhances the positive radiative effect of the black carbon aerosol.
\end{abstract}

\section{Introduction}

Atmospheric aerosol particles impact the atmospheric radiation budget directly and indirectly by modifying cloud microphysical properties. Both natural and anthropogenic aerosol species are relevant regarding interactions of aerosol and climate [1]. While aerosol radiative forcing usually refers to the radiative effect of anthropogenic aerosols in comparison to pre-industrial conditions, the aerosol radiative effect is due to aerosol species from both anthropogenic and natural sources. The effective radiative forcing of aerosols includes both the instantaneous forcing by aerosols and the so-called rapid adjustment of the atmosphere to aerosol forcing. This adjustment is mainly a consequence of heating rate changes from aerosol absorption and may impact atmospheric stability or cloud cover. Such adjustments are also named "semi-direct" effects. Absorbing aerosol types that cause semi-direct effects are black carbon (BC) particles and mineral dust. $\mathrm{BC}$ particles are strongly absorbing in the solar spectral range and cause a positive atmospheric direct radiative forcing at the top of atmosphere (TOA). BC is primarily emitted by combustion of fossil fuels or biomass including vegetation fires. While anthropogenic BC from fossil fuel burning usually remains within the boundary layer, $\mathrm{BC}$ from vegetation fires can be released several kilometers into the atmosphere and is subject to longdistance transport. The upper limit of estimates of the overall direct radiative effect for $\mathrm{BC}$ aerosol from both natural and anthropogenic sources is as high as $+0.9 \mathrm{Wm}^{2}[2]$.

Mineral dust from dry and unvegetated surfaces is also a partly absorbing aerosol type that may cause semidirect effects. Due to their large particle sizes dust particles have not only a shortwave but also an radiative effect in the terrestrial spectral range [3]. Mineral dust is mostly a natural aerosol type. The northern hemispheric

\footnotetext{
* Corresponding author: itegen@tropos.de
}

dust belt reaches from the Sahara over the Arabian Peninsula to the desert areas in Central Asia and China.

Aerosol semi-direct effects can be different. Possible effects are for example a reduction of vertical mixing as consequence of boundary layer stabilization [4], shifts of the inter-tropical convergence zone due to asymmetric absorbing aerosol forcing, or strengthening the southeast Asian monsoon circulation (e.g. [5]). Huang, et al. [6] found in a model study an increase in low cloud cover over oceans and some land regions, i.e. a negative semi-direct effect. However, the effects of absorbing aerosols on cloud cover and thus on temperature changes can be opposing, thus the semidirect effect is difficult to quantify on a global scale. Estimates of the radiative forcing due to the semi-direct effect range from -0.4 to $+0.1 \mathrm{Wm}^{-2}$. Local values of -9.5 to $+11 \mathrm{Wm}^{-2}$ have been estimated [7].

In this study we estimate the semi-direct aerosol effects by decomposing radiative forcing estimates from a global aerosol-climate model into direct, indirect and semi-direct forcings as in [8]. In that study it has been shown that the positive direct instantaneous and semidirect radiative effects of $\mathrm{BC}$ are more positive when forcing by mineral dust aerosol is considered together with the $\mathrm{BC}$ forcing, as the comparably bright dust aerosol enhances the positive $\mathrm{BC}$ forcing. This effect was mainly evident in the Sahel region and the tropical Atlantic. Here we focus on the Central Asian region where the effect of the dust on the semi-direct absorbing aerosol effect is evident in the seasonal rather than the annual means.

\section{Methods}

We investigate the semi-direct effects (or rapid adjustments) of the absorbing aerosol types $\mathrm{BC}$ and mineral dust within the global aerosol-climate model 
ECHAM6-HAM2 [9] (version echam6.3-ham2.3) at a resolution T63 and 47 vertical levels. ECHAM6 is the atmospheric general circulation model developed by the Max Planck Institute for Meteorology (MPIM) in Hamburg, Germany [10]. The aerosol module HAM (Hamburg Aerosol Model) predicts the evolution of an aerosol ensemble considering the species sulfate, black carbon (BC), organic carbon, sea salt, and mineral dust. The aerosol size spectrum is described by seven internally mixed log-normal modes (Nucleation mode, soluble (mixed) and insoluble Aitken, accumulation and coarse modes). Atmospheric radiative transfer is computed based on compounds present in the atmosphere and their related optical properties.

The radiative effects of absorbing aerosols were evaluated with four model experiments, summarized in Table 1. Each model simulation was averaged for 8 years (2003-2010). Sea surface temperatures were held fixed. The direct radiative and semi-direct radiative effects and radiative forcing by aerosol were computed with the method used in Ghan, et al. [11]. Radiative fluxes at the top of the atmosphere (TOA) are diagnosed as net solar and thermal fluxes and include scattering and absorption by clouds and aerosol particles. The direct radiative effect (DRE) of an aerosol type (BC, dust) is computed as difference between the radiative fluxes at TOA for the model simulation including the aerosol species and the simulation excluding this aerosol type. The instantaneous direct radiative effect (IDR) by the individual aerosol species is computed by double calls to the radiation routine. This diagnoses the instantaneous radiative effect without influencing the atmospheric conditions. The semi-direct effect (SDE) is subsequently calculated as residual of the direct radiative and the instantaneous radiative effect. The indirect effects of the aerosol particles on cloud microphysical properties are not considered here. The model simulations that are a subset of the simulations described in [8] are listed in Table 1.

Table 1. List of model experiments.

\begin{tabular}{|c|c|}
\hline Experiment & Aerosol types \\
\hline Base & All \\
\hline noBC & excluding BC aerosol \\
\hline noDust & excluding mineral dust \\
\hline noAbs & excluding BC and dust \\
\hline
\end{tabular}

\section{Results}

The absorbing aerosol optical depth has been evaluated against OMI retrievals in [8].

Figures 1 and shows the results for TOA IDR and SDE of BC without considering dust aerosol forcing, computed as difference of the forcing results for the experiments noABS-noDust for northern hemisphere summer (JJA).
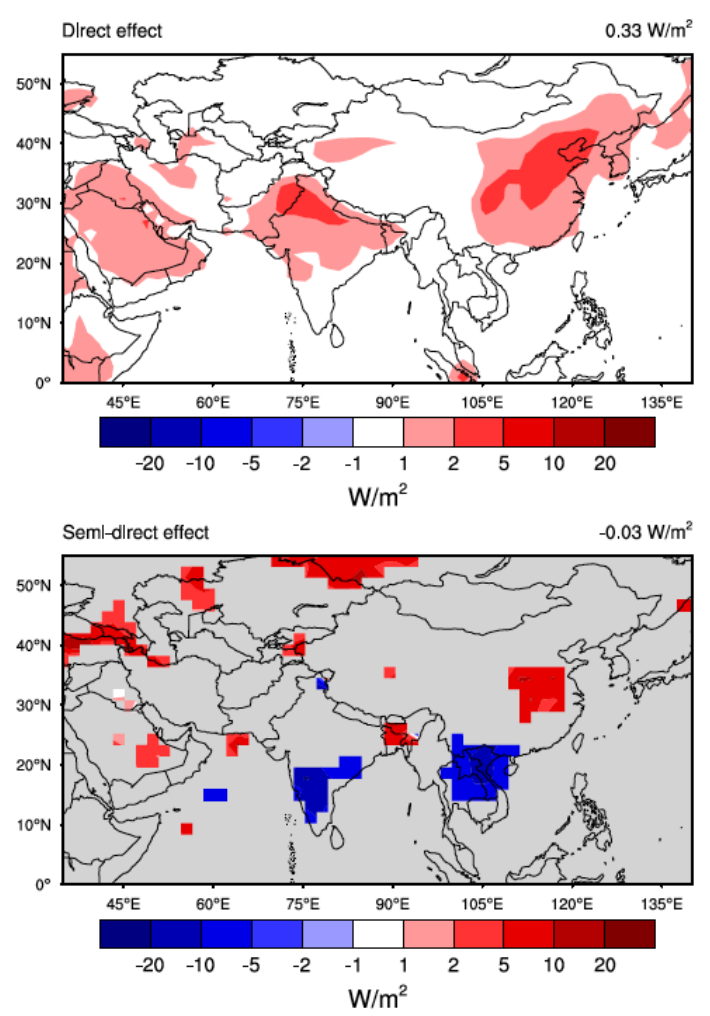

Fig. 1. (Top): Instantaneous $B C$ radiative effect (IDR) at TOA for JJA calculated from noABSnoDust. (Bottom): semi-direct effect (SDE) of BC at TOA. Dust forcing is not considered Grey areas indicate regions where the results are not statistically significant at $95 \%$ level.

The IDR of $\mathrm{BC}$ is positive and reflects the regions with highest $\mathrm{BC}$ loading in eastern Asia and northern India. Regionally positive forcing up to $5 \mathrm{Wm}^{-2}$ is calculated. The semi-direct effect is positive for eastern Asia but negative in south India (not at the location of the maximum forcing), primarily due to an enhancement in cloud cover. The direct and semi-direct effects are positive in Central Asia, however the results for the semi-direct effect are not statistically significant in most locations. 

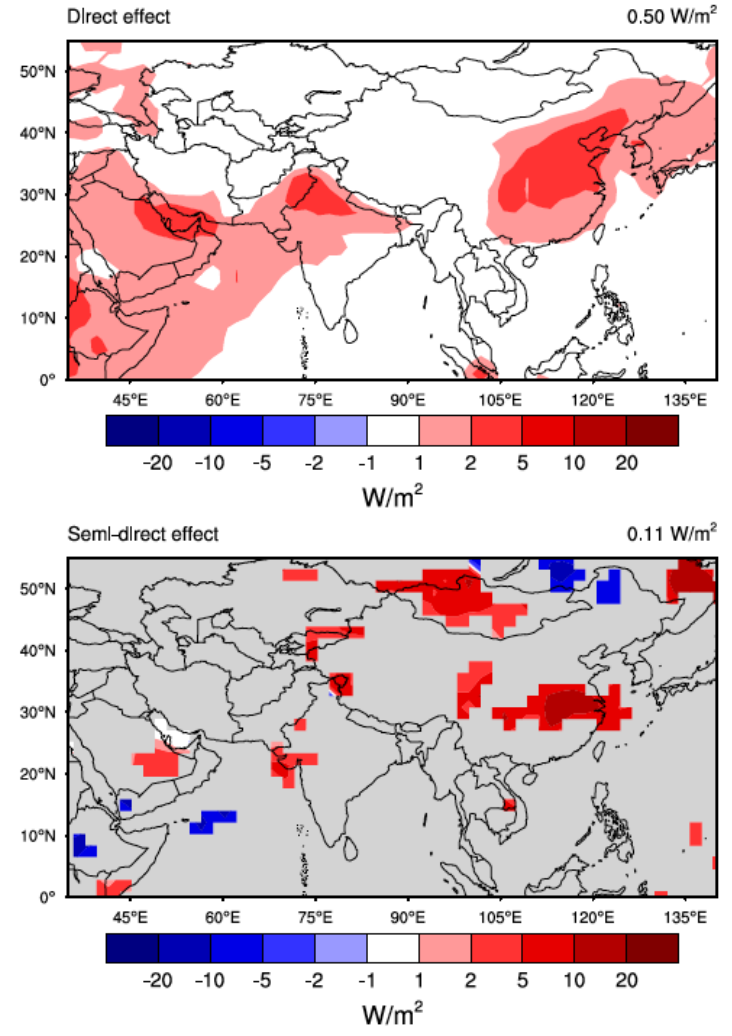

Fig. 2. As Fig. 1, but for noBC-BASE, including the dust in the computation of the radiative effect.
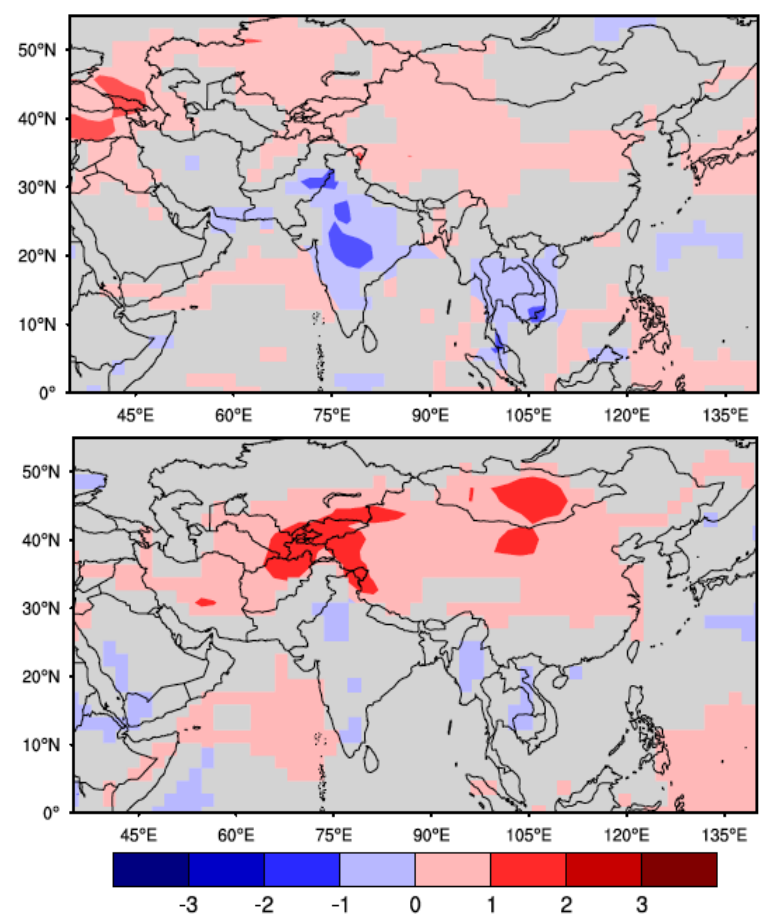

$\Delta \mathrm{T}(\mathrm{K})$

Fig. 3. $2 \mathrm{~m}$ temperature difference due to $\mathrm{BC}$ forcing for noABS-noDust (top) and noBC-BASE (bottom) including the mineral dust effect.

If dust is included (Figure 2) the $\mathrm{BC}$ forcing is more positive for both IDR and SDE. The increase in
IDR is a direct consequence of the increase in reflectivity due to the relatively brighter dust above the darker surface. The SDE is more positive in Central Asia as consequence of cloud reduction, and in East Asia it is nearly twice as high compared to the IDR.

Changes in 2-m surface temperature as consequence of $\mathrm{BC}$ forcing with and without considering dust aerosol are shown in Figure 3. The temperature change patterns follows mostly the SDE rather than the IDR forcing patterns. When dust is considered, significant warming of more than $1 \mathrm{~K}$ is simulated in Central Asia in JJA, while the cooling as consequence of cloud enhancement is reduced over the Indian subcontinent. While the semidirect effect and temperature change due to the effect of mineral dust itself (not shown) is small in this region, the effect of $\mathrm{BC}$ is more positive when the brighening by dust is taken into consideration.

\section{Conclusions}

The results of aerosol-climate model simulations presented in this study suggest that the presence of mineral dust may enhance the radiative effect due to $\mathrm{BC}$ absorption. In the model this effect enhances the warming due to $\mathrm{BC}$ aerosol in Central Asia in the northern hemisphere summer months. However, the overall effect is uncertain and may be model-dependent as simulated aerosol and cloud distributions contain uncertainties and the results may differ for different model sensitivities.

In these simulations the presence of mineral dust is also counteracting the effect of the strengthening of the Indian monsoon by BC heating. However the model results presented here are simulated with fixed sea surface temperatures as boundary condition, while such effects should rather be investigated within a fully coupled atmosphere-ocean climate model. For the interior of the continent the results are less impacted by potential sea surface temperature changes and may be more robust.

The authors are grateful for computing resources granted at DKRZ, Hamburg, Germany. The ECHAM-HAMMOZ model is developed by a consortium composed of ETH Zurich, Max Planck Institute for Meteorology, Research Center Jülich, University of Oxford, the Finnish Meteorological Institute and the Leibniz Institute for Tropospheric Research, and managed by the Center for Climate Systems Modeling (C2SM) at ETH Zurich.

\section{References}

1. C.L. Heald; D.A. Ridley; J.H. Kroll; S.R.H. Barrett; K.E. Cady-Pereira; M.J. Alvarado; C.D. Holmes. Contrasting the direct radiative effect and direct radiative forcing of aerosols. Atmos. Chem. Phys. 14, 5513-5527 (2014) 
2. IPCC. Climate change 2013: The physical science basis. Contribution of working group $i$ to the fifth assessment report of the intergovernmental panel on climate change. Cambridge University Press: Cambridge, United Kingdom and New York, NY, USA, 2013; p 1535, (2013)

3. A.A. Lacis; M.I. Mishchenko. Climate forcing, climate sensitivity, and climate response: A radiative modeling perspective on atmospheric aerosols. In Aerosol forcing of climate: Report of the dahlem workshop on aerosol forcing of climate, Charlson, R.J.; Heintzenberg, J., Eds. John Wiley Sons: Chichester, England / New York (1994)

4. M. Wendisch; O. Hellmuth; A. Ansmann; J. Heintzenberg; R. Engelmann; D. Althausen; H. Eichler; D. Müller; M. Hu; Y. Zhang, et al. Radiative and dynamic effects of absorbing aerosol particles over the pearl river delta, china. Atmospheric Environment 42, 64056416 (2008)

5. Y. Ming; V. Ramaswamy. Nonlinear climate and hydrological responses to aerosol effects. Journal of Climate 22, 1329-1339 (2009)

6. J. Huang; T. Wang; W. Wang; Z. Li; H. Yan. Climate effects of dust aerosols over east asian arid and semiarid regions. Journal of Geophysical Research: Atmospheres 119, 11,398-311,416 (2014)

7. D. Koch; A.D. Del Genio. Black carbon semidirect effects on cloud cover: Review and synthesis. Atmos. Chem. Phys. 10, 7685-7696 (2010)

8. I. Tegen; B. Heinold. Large-scale modeling of absorbing aerosols and their semi-direct effects. Atmosphere 2018, accepted.

9. K. Zhang; D. O'Donnell; J. Kazil; P. Stier; S. Kinne; U. Lohmann; S. Ferrachat; B. Croft; J. Quaas; H. Wan, et al. The global aerosolclimate model ECHAM-HAM, version 2: Sensitivity to improvements in process representations. Atmos. Chem. Phys. 12, 89118949 (2012)

10. B. Stevens; M. Giorgetta; M. Esch; T. Mauritsen; T. Crueger; S. Rast; M. Salzmann; H. Schmidt; J. Bader; K. Block, et al. Atmospheric component of the mpi-m earth system model: ECHAM6. Journal of Advances in Modeling Earth Systems, 5, 146-172 (2013)

11. S.J. Ghan; X. Liu; R.C. Easter; R. Zaveri; P.J. Rasch; J.-H. Yoon; B. Eaton. Toward a minimal representation of aerosols in climate models: Comparative decomposition of aerosol direct, semidirect, and indirect radiative forcing. Journal of Climate 25, 6461-6476 (2012) 